\title{
Religião, comunidades terapêuticas e projeto ético- político do Serviço Social
}

\author{
Religion, therapeutic communities, and social work's ethical- \\ political project
}

\author{
Vinicius Pinheiro de Magalhães* \\ Vera Núbia Santos**
}

\begin{abstract}
Resumo - O texto busca refletir sobre religião e comunidades terapêuticas, na perspectiva da saúde mental, e propõe problematizar a mediação dos conceitos de laicidade e apoio social. Sinaliza a necessidade de defesa intransigente dos direitos humanos e o fortalecimento da Rede de Atenção Psicossocial (Raps), expressões claras do projeto ético-político (PEP) do Serviço Social brasileiro, ameaçadas na atual conjuntura do país, de cariz ultraconservador. Considera que a necessidade da religiosidade como elemento de apoio social para lidar com o sofrimento mental que decorre dos problemas com o uso abusivo de álcool e outras drogas é inversamente proporcional ao financiamento e pleno funcionamento da Raps e que se faz mister retomar a defesa da reforma psiquiátrica.
\end{abstract}

Palavras-chave: Serviço Social; saúde mental; comunidades terapêuticas; religião/religiosidade.

\begin{abstract}
The article seeks to reflect on religion and Therapeutic Communities, from the perspective of Mental Health, and proposes to discuss the mediation between concepts of secularity and social support. It signals the need for uncompromising defense of human rights and the strengthening of the Psychosocial Care Network (RAPS), clear expressions of the Ethical-Political Project (PEP) of Brazilian Social Work, which is being threatened in the current ultra-conservative trends in the country. It considers that the need for religiosity as an element of social support to deal with the mental suffering that arises from problems with the abuse of alcohol and other drugs is inversely proportional to the financing and full functioning of RAPS and that it is essential to resume the defense of the Psychiatric Reform.

Keywords: social work; mental health; Therapeutic Communities; religion/religiosity.
\end{abstract}

\footnotetext{
* Assistente Social formado pela Universidade Federal do Recôncavo da Bahia (UFRB). Mestre em Serviço Social pela Universidade Federal de Sergipe (UFS). Residente Multiprofissional em Saúde Mental pelo Hospital Universitário Prof.․․ㅁ. Dr. Edgard Santos da Universidade Federal da Bahia (HUPES/UFBA). E-mail: viniciuspmaga@gmail.com. ORCID: http://orcid.org/0000-0002-2909-3517.

** Assistente social formada pela Universidade Federal de Sergipe (UFS). Mestre e Doutora em Serviço Social pela Pontifícia Universidade Católica de São Paulo (PUC/SP). Docente efetiva do Departamento e do Programa de Pós-graduação em Serviço Social da Universidade Federal de Sergipe (UFS). E-mail: venus_se@uol.com.br. ORCID: http:// orcid.org/0000-0002-9040-7140.
} 


\section{Introdução}

A realidade política do Brasil hodierno tem apresentado a ascensão de um segmento conservador na gestão do aparelho do Estado. Tal projeto, além de reacionário em face de valores democráticos, mostra-se eivado por uma ideologia de confessionalidade neopenteconstal do submundo evangélico, segmento religioso notadamente fundamentalista. Cabe ressaltar que, para Mariano (2004, p. 123-124), os protestantes neopentecostais caracterizam-se

[...] pelo anticatolicismo, por radical sectarismo e ascetismo de rejeição do mundo. No plano teológico, enfatizaram o dom de línguas (glossolalia), seguindo a ênfase doutrinária primitiva dessa religião. [...] [além de] conferirem ênfase teológica à cura divina, seguindo o bem-sucedido movimento de cura propagado nos Estados Unidos durante a Segunda Guerra Mundial. [Já os neopentecostais] caracterizam-se por enfatizar a guerra espiritual contra o Diabo e seus representantes na terra, por pregar a Teologia da Prosperidade, difusora da crença de que o cristão deve ser próspero, saudável, feliz e vitorioso em seus empreendimentos terrenos, e por rejeitar usos e costumes de santidade pentecostais, tradicionais símbolos de conversão e pertencimento ao pentecostalismo.

O conservadorismo de costumes une-se à agenda ultraliberal de redução do Estado na condução da economia, o que, em última instância, aprofunda uma gestão pública de mínimo para o social e máximo para o capital. Essa realidade política e social reverbera de forma substantiva no campo da saúde mental, culminando em processos de desfinanciamento e sucateamento de políticas construídas a duras penas a partir de intervenções dos movimentos sociais. Nessa direção, a reflexão sobre as instituições imagem e semelhança da ideologia do atual governo federal - comunidades terapêuticas para o tratamento de usuários de álcool e outras drogas mostra-se relevante, sobretudo, por esta empreitada demandar cuidados diante da análise das reais necessidades dos usuários de tais serviços.

O objetivo do presente ensaio teórico é refletir sobre a relação religião-comunidades terapêuticas, propondo problematizações a partir da mediação dos conceitos de laicidade e apoio social, donde procuramos sinalizar a necessidade de defesa intransigente dos direitos humanos e do fortalecimento da Rede de Atenção Psicossocial (Raps), expressões claras do projeto ético-político (PEP) do Serviço Social, as quais se evidenciam ameaçadas na contemporaneidade.

O presente texto é fruto da dissertação de mestrado intitulada Serviço Social, (des)patologização da vida e religiosidade em Saúde Mental, defendida em fevereiro de 2020 no Programa de Pós-Graduação em Serviço Social da Universidade Federal de Sergipe (Pross/UFS) e aprovada com orientação à publicação. Trata-se de uma revisão de literatura que con- 


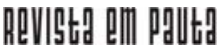

\} RELIGIÃO, COMUNIDADES - MAGALHÃES, V. P.; SANTOS, V. N.\}

DOI: $10.12957 /$ REP.2022.63447

formou reflexões conclusivas de pesquisa de abordagem qualitativa e natureza exploratória, donde se utilizou o instrumento da entrevista semiestruturada para a coleta de dados junto a profissionais do Serviço Social, os quais tiveram suas considerações analisadas pela via da análise de conteúdo por categorização temática. O trabalho foi realizado com apoio da Coordenação de Aperfeiçoamento de Pessoal de Nível Superior - Brasil (Capes) - código de financiamento 001.

\section{Relação religião-comunidades terapêuticas: a particularidade brasileira}

Não é muito difícil traçar o motivo da discórdia entre a perspectiva ídeo-teórica que baliza o PEP profissional do Serviço Social e as comunidades terapêuticas brasileiras. As comunidades terapêuticas nasceram no segundo pós-guerra na tentativa de humanizar os hospitais psiquiátricos, lócus de verdadeiros supliciamentos do corpo do louco' ${ }^{1}$. É com Maxwell Jones na Inglaterra que esta proposta de humanização dos hospitais psiquiátricos consagra-se no termo comunidade terapêutica.

A proposta de Jones era a de humanizar o tratamento, as relações entre profissionais da saúde e os internos. Ainda que alvo de críticas substantivas de membros da antipsiquiatria e da psiquiatria democrática italiana, a exemplo de Franco Basaglia, tratou-se de uma experiência reformista que inaugurou as possibilidades de se colocar em xeque o modelo manicomial de tratamento. Apresentou uma verdadeira democratização na dimensão intra-hospitalar, a construção de uma comunidade:

[...] a idéia [sic.] de comunidade terapêutica pauta-se na tentativa de 'tratar grupos de pacientes como se fossem um único organismo psicológico'. Mais que isso, através da concepção de comunidade, procura-se desarticular a estrutura hospitalar considerada segregadora e cronificadora: o hospital deve ser constituído de pessoas, doentes e funcionários, que executem de modo igualitário as tarefas pertinentes ao funcionamento da instituição. Uma comunidade é vista como terapêutica porque é entendida como contendo princípios que levam a uma atitude comum, não se limitando somente ao poder hierárquico da instituição. (AMARANTE, 1995, p. 29).

A comunidade terapêutica, todavia, ao estender-se pelo mundo, não se manteve fiel à sua natureza clássica. A este respeito, Cavalcante (2019) afirma que no mesmo período de vigência da comunidade terapêutica de Maxwell Jones, emergente de um processo de reforma psiquiátrica

\footnotetext{
${ }^{1}$ Loucura aqui não se associa ao seu sentido pejorativo, negativo, imediatamente relacionado à periculosidade, irracionalidade e incapacidade de transferência e autogestão, mas à perspectiva assumida pela luta antimanicomial, a qual tem disputado tal sentido, tensionando possibilidades narrativas de associação positiva a partir da mediação com os conceitos de cidadania, autonomia e liberdade.
} 
em curso, desenvolve-se, também, a vertente estadunidense, centrada no tratamento de usuários de drogas e num modelo de reforma moral individualista. Duas tendências em cena; de um lado uma comunidade terapêutica reformista, fomentadora de práticas democráticas e humanizadoras no contexto do hospital psiquiátrico, de outro uma comunidade terapêutica restrita a usuários de drogas, a qual reatualiza o tratamento moral individual da perspectiva manicomial.

Destaca-se a correspondência econômico-social destas duas vertentes. A experiência inglesa, onde o Estado de bem-estar social consolidouse numa perspectiva universalista, de maior inclusão e equidade no acesso às políticas sociais, traz uma tendência de tratamento do louco numa abordagem democrática, de promoção de empoderamento. Doutra sorte, na experiência estadunidense, onde o Estado de bem-estar social consolidouse num direcionamento meritocrático e focalizador, o que restringiu - e ainda restringe - $\mathrm{o}$ acesso às políticas sociais, a abordagem de tratamento na comunidade terapêutica foi balizada numa perspectiva moralizadora individualista, o que refletiu a natureza substantivamente meritocrática da forma de gestão econômico-social do país.

Nessas experiências, a natureza das comunidades terapêuticas foi conformada por elementos econômico-sociais e culturais. No caso do Brasil não foi diferente. Aqui não se consolidou um Estado de bem-estar social amplo ou meritocrático. Na periferia do mundo capitalista, até em seus melhores períodos econômico-sociais, desenvolveu-se um processo de significativa exclusão, realidade que é exponenciada em tempos de neoliberalismo; eis os determinantes para a emergência e o campo de atuação das comunidades religiosas (neo)pentecostais que atuam no combate às drogas.

Desse modo, as comunidades terapêuticas no Brasil foram conformadas a partir de uma aproximação com o modelo norte-americano, centrado na reforma moral individual, mas balizado por elementos culturais específicos da formação social brasileira, dos quais se destaca a religiosidade e sua característica de lidar com situações existenciais e sociais limite (VASCONCELOS, 2019; CAVALCANTE, 2019).

Assim surgem as comunidades terapêuticas confessionais no Brasil, mas qual a relação da confessionalidade com a perspectiva de abstinência no tratamento de pessoas com problemas devido ao uso abusivo de álcool e outras drogas, principal elemento de discórdia com a perspectiva ídeoteórica do PEP profissional, defensora da política de redução de danos²? Em nossa perspectiva é o fundamentalismo religioso, o qual caracteriza muitas das igrejas pentecostais e neopentecostais que se aventuram na gestão

\footnotetext{
2 "[...] A redução de danos consiste em um repertório de cuidado, constituído de um conjunto de estratégias singulares e coletivas voltadas para as pessoas que usam, abusam ou dependem de drogas. Incluem-se nas estratégias de prevenção a recomendação do não compartilhamento de instrumentos e a utilização de materiais descartáveis, inclusive para o uso de silicone industrial e hormônios entre pessoas trans" (BRASIL, 2019a, n. p.).
} 


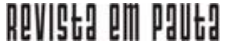

\} RELIGIÃO, COMUNIDADES - MAGALHÃES, V. P.; SANTOS, V. N. \}

DOI: $10.12957 /$ REP.2022.63447

de comunidades terapêuticas brasileiras, que explica a aderência à perspectiva de tratamento focado na abstinência. "Fundamentalistas são os defensores do que julgam ser os fundamentos da sua religião, quando sentem que estão sendo atacados" (AMALADOSS, 2002, p. 182).

Podem-se considerar fundamentalistas não apenas segmentos das religiões do livro (cristianismo, judaísmo e islamismo), mas todo o sistema de pensamento que se pretende dogmático, segregador e que negue a existência de outros grupos da sociedade (ex.: nazismo, apartheid, fascismo etc.). Entretanto, a origem do fundamentalismo remonta ao protestantismo americano, quando de um movimento de resistência à modernidade:

O nascimento do movimento fundamentalista se insere no centro da modernidade. Esta foi o emergir da consciência autônoma, histórica e crítica. Ante a modernidade, o fundamentalismo apresenta-se como via de 'mão dupla'. De um lado, ele é resultado desta modernidade crítica, secularizada, individualizante e pluralizada. De outro lado, é uma reação à modernidade ocidental, liberal e tecnocrática. (PANASIEWICZ, 2010, p. 1).

A teologia americana moderna acompanhou o progresso científico e a mudança de paradigma da explicação sobre o processo de organização da sociedade, i.e., a organização social e as relações sociais deixavam de ser explicadas como fruto de determinantes místicos e religiosos e passavam a ter fundamentações científicas.

A teologia liberal, nome dado à teologia que dialogou com a ciência moderna, surgiu para colocar em xeque os pressupostos antiquados da fé cristã, bem como seus dogmas enrijecidos, tendo como característica central a relativização de alguns fundamentos conservadores da religião. Como resistência à teologia liberal moderna surgiu o fundamentalismo protestante americano, protagonizado pelas denominações metodista e presbiteriana, que se uniram na produção das chamadas cartilhas dos fundamentos da fé. Essas cartilhas e/ou panfletos explicitavam alguns fundamentos inegociáveis da fé cristã, a exemplo do nascimento virginal de Jesus, Divindade de Jesus, Salvação apenas em Jesus etc. (CORDEIRO, 2009).

Desse movimento de resistência à teologia liberal moderna emerge uma nova forma de ler/interpretar os textos da Bíblia, ou seja, uma nova teologia. Trata-se de uma teologia que tem desconsiderado hermenêuticas dos textos bíblicos, os quais dialogam com a história e com a modernidade. Esta forma de interpretação da Bíblia é que vai legitimar o dogma e a doutrina em detrimento da valorização dos direitos humanos, defendidos pela teologia liberal moderna.

Esse movimento, baseado numa forma rígida e purista de interpretação do texto bíblico, por não dialogar com a história, sente-se constantemente ameaçado, o que reverbera num processo de demonização da alteridade que considera maléfica: 
Defendem o milenarismo apocalíptico. Alimentam 'a visão apocalíptica do combate final entre o bem e o mal, interpretando uma necessidade social emergente entre os indivíduos: o medo de perder as próprias raízes, de perder a identidade coletiva'. O mal assume várias dimensões e fisionomias e necessita ser combatido. (PANASIEWICZ, 2010, p. 3).

A partir daí surgem as diversas violências aos segmentos LGBTQ+, à cultura negra e aos pagãos, todas fruto de uma interpretação desistoricizada do livro e carregadas de intolerância em nome de uma fé purista. Amaladoss (2002, p. 182-183) ressalta que a intolerância desses grupos se voltou, posteriormente, contra o comunismo, numa "oposição [que] está por trás da construção da grande máquina de guerra que são hoje os EUA. Práticas de moral liberal, tal como o aborto, também atraíram a sua oposição".

Acrescente-se aos alvos demonizados pelos fundamentalistas a questão das drogas, perseguição que apresenta claros nexos históricos com aquela impetrada pelas classes dominantes às populações preta e indígena na realidade brasileira. No Brasil, o fundamentalismo teve maior capilaridade em segmentos do protestantismo e do catolicismo que são mais proselitistas (neopentecostais e carismáticos), o que justifica a ocupação das mídias de comunicação para a propagação de sua mensagem.

O que se quer ressaltar, portanto, é que a natureza fundamentalista dos segmentos do neopentecostalismo brasileiro, estruturada em dogmas rígidos e desistoricizados, os quais estabelecem alvos a serem demonizados (LGBTQ+, cultura negra, drogas etc.) numa verdadeira abordagem de batalha espiritual, legitima a inegociabilidade do tratamento das drogas baseado na abstinência. Isso, em última instância, relaciona-se a uma proibição moral do uso de álcool e outras drogas em tais comunidades religiosas.

O proibicionismo como ideologia e política pública não tem apenas uma correspondência subjetiva com o fundamentalismo religioso, mas também é determinado por interesses econômicos objetivos, na medida em que

[...] colabora com o avanço do Estado no campo penal e na ampliação da repressão militarizada (ao mesmo tempo em que o Estado amplia o desmonte das políticas sociais), que criminaliza a pobreza em nome da manutenção da ordem e dos mecanismos de controle social sobre as classes populares, adquirindo ampla funcionalidade para determinados setores do capital como a indústria de armas, as empresas de segurança, o sistema financeiro (que lava dinheiro do narcotráfico aos paraísos fiscais) e setores religiosos, principalmente os mais conservadores. (DENADAI, 2019, p. 366).

É no contexto de divulgação de uma narrativa sobre uma epidemia de crack que essas comunidades terapêuticas crescem e se desenvolvem no Brasil, propondo um tratamento de cariz significativamente religioso cujo 


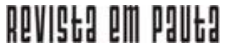

\} RELIGIÃO, COMUNIDADES - MAGALHÃES, V. P.; SANTOS, V. N. \}

DOI: $10.12957 /$ REP.2022.63447

objetivo é a abstinência (CAVALCANTE, 2019). Trata-se de comunidades que passam a ser reconhecidas pelo Estado e são institucionalizadas, ou seja, legitimadas e financiadas pelo poder público a fim de fazer parte da Rede de Atenção Psicossocial. Este processo de institucionalização ocorre a despeito das seguintes tendências comprovadas de violações dos direitos humanos:

Interceptação e violação de correspondências, imposição de credo e exigência de exames clínicos, como o teste de HIV, obrigatoriedade de execução de tarefas cotidianas de manutenção da estrutura física da instituição [...] hipermedicalização e até mesmo imposição de abstinência sexual e desrespeito ao direito de livre orientação sexual e identidade de gênero. (BICALHO; BARBOSA; SIMÕES, 2019, p. 314).

A lógica manicomial parece reatualizar-se na experiência das comunidades terapêuticas brasileiras, na medida em que diversas violações dos direitos humanos têm sido denunciadas a partir de sua atuação. Além da abstinência como forma de tratamento e das diversas violações dos direitos humanos, a perspectiva ídeo-teórica do PEP profissional se opõe a estas instituições por representarem as tendências de desfinanciamento das políticas sociais públicas e de desresponsabilização do Estado de suas obrigações sociais.

\section{Os conceitos de laicidade e apoio social no contexto da saúde mental: possíveis nexos de convergência com o PEP profissional}

A despeito do fato de as comunidades terapêuticas ofertarem um tratamento confessional desumano, nota-se que a procura por tais dispositivos conservadores expressa uma demanda anunciada pelas classes populares, o que coloca em cena o debate sobre o princípio moderno da laicidade do Estado e sua expressão nas instituições públicas de saúde mental.

O debate sobre a laicidade é delicado no cenário da sociabilidade brasileira, marcada por uma cultura religiosa e sua característica de lidar com situações existenciais e sociais limite, agudizadas na periferia do capitalismo mundial. O Estado não é um ente abstrato que paira acima dos homens, mas uma instituição burguesa que se movimenta de acordo com interesses específicos, espaço disputado por classes antagônicas. Desse modo, o Estado é constituído por indivíduos representantes destes interesses de classe, os quais também receberam ingerência da cultura em sua formação pessoal. Dito de outro modo, o Estado, apesar de pretensamente laico, é ocupado e gerido por pessoas não laicas. 


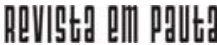

\} RELIGIÃO, COMUNIDADES - MAGALHÃES, V. P.; SANTOS, V. N. \}

DOI: $10.12957 /$ REP.2022.63447

Este debate também assume contornos particulares no âmbito do Serviço Social. Trata-se de uma profissão que se conformou hegemonicamente contrária a uma atuação profissional confessional e conservadora e assumiu um projeto profissional balizado na defesa intransigente dos direitos humanos, tendo a liberdade e a democracia como princípios éticos fundamentais. Todavia, como que reatualizando o dilema do Estado, o Serviço Social também é composto por um grande contingente de pessoas religiosas. Tais problemáticas demandam rigor na reflexão sobre a laicidade.

Ranquetat Jr. (2008) recorre ao pensamento de Maurice Barbier a fim de conceituar a laicidade em seus sentidos de neutralidade-exclusão e neutralidade-imparcialidade. A laicidade como neutralidade-exclusão é a dimensão da exclusão da religião do espaço público. De forma complementar, a laicidade como neutralidade-imparcialidade é o aspecto da imparcialidade diante das expressões religiosas ou de ausência de crença, é um posicionamento do Estado caracterizado pelo tratamento isonômico a toda forma de espiritualidade, por sua ausência de preferência religiosa. Uma consequência natural da efetivação destas duas dimensões de laicidade é a garantia de um direito civil fundamental, a liberdade de crença.

A laicidade alijada de uma destas dimensões perde sua substância, contraria sua natureza. Pensar laicidade como, somente, a exclusão da influência religiosa no âmbito do Estado pode engendrar abordagens déspotas, as quais desconsideram a liberdade de crença como um direito humano. Noutra direção, pensar laicidade apenas como uma imparcialidade diante da liberdade de crença, sem empreender medidas para neutralizar sua influência no contexto do Estado, pode legitimar abordagens proselitistas, preconceituosas e de violação dos direitos da diversidade humana.

O risco de se confundir as dimensões da laicidade é o risco de associá-la ao laicismo. A este respeito, Ranquetat Jr. (2008) reflete sobre as características e os fundamentos destas duas tendências históricas. O autor afirma que laicidade não advém de uma demanda religiosa, mas política. Sua conformação devém de forças políticas organizadas, o que torna sua efetivação algo diferenciado e particular em cada país.

Todavia, é possível demarcar um movimento mais amplo que culminou com a laicidade dos diversos Estados-Nação. Este movimento amplo é um processo de ruptura com a pré-modernidade, a Idade Média, marcada pela ingerência da religião na organização da sociedade. $\mathrm{O}$ processo de ruptura com a influência confessional na dinâmica de ordenamento das relações sociais é denominado de secularização. A instituição de um Estado laico, em sua diversidade de facetas, pressupõe, desse modo, um processo de secularização (RANQUETAT JR. 2008; NASCIMENTO, 2016).

Certamente que esse processo de secularização assumiu particularidades em contextos como o nosso, onde as instituições da República e da revolução burguesa deram-se mediante um acordo entre o velho poder 


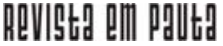

\} RELIGIÃO, COMUNIDADES - MAGALHÃES, V. P.; SANTOS, V. N. \}

DOI: $10.12957 /$ REP.2022.63447

oligárquico e a força burguesa ascendente (FERNANDES, 2006), o que justifica, por exemplo, nossos feriados e símbolos religiosos em instituições públicas; as rezas e orações em sessões de conselhos de direitos e do legislativo e a promulgação da Constituição Federal de 1988, considerada uma constituição socialdemocrata, sob a proteção de Deus (CFESS, 2016).

Ranquetat Jr. (2008), além de discutir sobre esse processo histórico determinante para a laicidade, conceitua outra tendência histórica, a do laicismo. Diferente da laicidade, determinada por um lento processo de secularização, o qual sintetizou um princípio de dever-ser do Estado em relação à dimensão da religião, o laicismo é uma expressão que caracteriza experiências históricas que objetivaram o extermínio da religião e de sua influência. O laicismo foi uma tentativa militante de secularização.

O pensamento liberal, um dos grandes divulgadores do ideal de laicidade, a despeito de sua proposta de Estado neutro, tornou-se uma fé laica (RANQUETAT JR., 2008, p. 74), isto é, uma ideologia proselitista que reverberou em muitos movimentos anticlericais, "[...] em muitos casos os grupos laicistas, secularistas, se mostraram em diversas oportunidades históricas anticlericais e eivados de preconceitos antirreligiosos o que acarretou inclusive perseguições violentas contra instituições, pessoas e símbolos religiosos" (RANQUETAT JR., 2008, p. 75).

O pensamento liberal quando se reveste de um invólucro religioso e proselitista se assemelha aos movimentos sanguinários da Igreja de Roma à época das Cruzadas inquisitoriais. Ademais, o laicismo, nesse sentido de secularização impositiva e violenta, também pode ser associado às diversas experiências de socialismo real onde a religião foi duramente perseguida e combatida (BETTO, 2015). Percebe-se, desse modo, que o laicismo parece ser a extrapolação de uma das facetas da laicidade, a exclusão da religião da dimensão estatal, mas também da sociedade.

Está claro que os profissionais da saúde, inclusive os de Serviço Social, não devem assumir posturas proselitistas e religiosas em seus espaços sócio-ocupacionais, pois representam o Estado no exercício público de suas funções. Contudo, esse dever-ser profissional, correspondente à defesa da laicidade no seu sentido de neutralidade-exclusão, não deve prescindir da defesa da liberdade religiosa da sociedade, dos usuários dos serviços públicos das políticas sociais, sob o risco de assistentes sociais associaremse à perspectiva laicista, isto é, a uma tendência militante e violenta de secularização.

Dito de outro modo, os profissionais da saúde não devem atuar direcionados por suas crenças religiosas, o que não significa que devem neutralizar a experiência religiosa de usuários, a qual surge de forma espontânea como um traço de sua formação cultural. Nesse sentido, concordamos com a reflexão feita por Regis do Nascimento (2016) ao dialogar com o pensamento do humanista alemão Jörn Rüsen, para quem a laicidade deve ser praticada evocando a ideia de reconhecimento, 
[...] onde não deve haver a rejeição do outro, o apagamento das diversas religiosidades e culturas dos universos individuais, e sim o contrário, [...] a conscientização da pluralidade, a identificação de pontos em comum com o outro, o contato com outras religiões. Não estamos aqui defendendo um contato invasivo, mas um contato conciliador, para estimular e possibilitar na sociedade o reconhecimento de um humanismo pleno, onde todos, mesmo com religiões diferentes, são merecedores de desfrutar de uma dignidade humana igual. (NASCIMENTO, 2016, p. 11).

Laicidade como uma dimensão que evoca o reconhecimento por parte do Estado e dos profissionais que o representam - da diversidade de crenças como um direito, como uma dimensão legítima de necessidade humana, a qual, em determinados contextos, assume a função de apoiadora social.

A cultura religiosa dos brasileiros está em mudança significativa. O número de evangélicos, sobretudo os de tradição (neo)pentecostal, tem crescido substantivamente, conforme informações dos últimos Censos do Instituto Brasileiro de Geografia e Estatística (IBGE). Algumas previsões dedutivas sugerem que em poucas décadas haverá mais evangélicos que católicos no Brasil (VASCONCELOS, 2019).

Analistas da esquerda e da tradição da Teologia da Libertação têm explicado este fenômeno do crescimento das comunidades pentecostais e neopentecostais, a despeito das previsões de desencantamento do mundo, como expressão das tendências de alienação, dominação de classe e de um alheamento da realidade, um escapismo sobrenatural (VASCONCELOS, 2019). Todavia, outra tendência explicativa no espectro da esquerda sobre o fenômeno da ascensão de templos (neo)pentecostais no contexto da periferia do capitalismo emergiu a partir das reflexões empreendidas pelo exprofessor, falecido em 2009, da Escola Nacional de Saúde Pública da Fiocruz no Rio de Janeiro, Victor Vincent Valla, um dos precursores do Movimento de Educação Popular em Saúde.

Victor Valla (2001) contextualizou o fenômeno religioso ao movimento do capitalismo mundial, o qual impacta de forma negativa em países com significativo empobrecimento da população, como é o caso do Brasil. É neste contexto de sucateamento das políticas sociais públicas que a demanda pelos serviços de saúde aumenta, obrigando as instituições públicas a assumirem maior resolutividade, o que implica atendimentos rápidos e, não poucas vezes, rasos.

Desse modo, Valla (2001) chama atenção para o fato de que os profissionais de saúde que trabalham nesse quadro têm poucas condições de lidar com um problema constante que tem se manifestado nas classes populares, uma queixa identificada como sofrimento difuso: "Uma queixa sobre dores de cabeça, dores em outros locais do corpo, medo, ansiedade - sintomas para quais o sistema de saúde não tem nem tempo ou recursos 


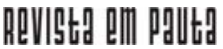

\} RELIGIÃO, COMUNIDADES - MAGALHÃES, V. P.; SANTOS, V. N. \}

DOI: $10.12957 /$ REP.2022.63447

para tratar. O resultado é a medicalização do problema" (VALLA, 2001, p. 118). Em face de tais problemáticas, desenvolve-se a teoria do apoio social:

A proposta central do apoio social é melhorar a saúde das pessoas envolvidas em grupos diversos (associação, vizinhança, igreja, por exemplo). Esse apoio normalmente se passaria entre pessoas que se conhecem e de uma forma sistemática, razão pela qual frequentemente está envolvida uma instituição ou entidade. (VALLA, 2001, p. 120-121).

O autor enfatiza, ainda, que as classes populares sofrem de forma mais intensa os impactos dos ambientes estressores, o que os condicionam a viverem em contínuo estado de alerta - sobretudo aquelas que sobrevivem em contextos periféricos, onde a violência é uma realidade cotidiana -, além de possuírem menos alternativas para o enfrentamento do sofrimento difuso.

Neste cenário de desfinanciamento das políticas sociais, de impasse para a incorporação de demandas ao serviço público de saúde e de sofrimento difuso das classes populares, determinado por ambientes estressores, que as igrejas e a religião se tornam meios estratégicos para a sobrevivência, uma vez que se configuram espaços de apoio social.

Valla (2001, p. 126) chama atenção para o fato de que a manipulação de líderes religiosos, interessados em seu enriquecimento e capital político, o que, muitas vezes, é legitimado pelas classes populares, não explica a demanda pela procura da dimensão religiosa. Há uma necessidade de "[...] um sentido, algo que torne a vida mais coerente - justamente uma das propostas do apoio social". Trata-se daquilo que Eduardo Vasconcelos (2019), ao analisar a função social da religião no contexto da saúde mental, chamou de um mecanismo que possibilita lidar com situações existenciais e sociais limite. Esclarece-se, desse modo, os motivos de a religião e a religiosidade servirem como dimensões positivas no processo de tratamento do sofrimento mental decorrente do uso de álcool e outras drogas, o que se relaciona mais ao fato de tal dimensão da cultura viabilizar a comunhão contínua de pessoas no mesmo espaço físico que à ingerência das lideranças religiosas.

Victor Valla (1996, 2001), ao recorrer à teoria do apoio social, inaugura, no espectro da tradição marxista brasileira, uma nova forma de compreender a religiosidade popular, não como conformista e alienada, mas como expressão daquilo que Cristian Parker (1996) chamou de protesto simbólico e Marilena Chauí (1990) suspeitou tratar-se de uma inconformidade escondida atrás de uma postura de fatalismo. A aderência à religiosidade popular representa um protesto contra a desassistência estatal, contra a lógica de gerência das políticas sociais, que não viabiliza a incorporação de demandas relacionadas aos sofrimentos difusos das classes populares. Nessa perspectiva, a religiosidade não é um mecanismo de con- 
formação fatalista, mas uma expressão de denúncia, "[...] o protesto contra a miséria real. A religião é o suspiro da criatura oprimida, o ânimo de um mundo sem coração, assim como o espírito de estados de coisas embrutecidos" (MARX, 2010, p. 145).

Reivindica-se, na religiosidade popular, uma vida plena na imanência. Procura-se a cura, o milagre, a provisão, a restauração e a prosperidade. Busca-se a assistência e o bem-estar que o Estado não foi capaz de garantir. Dar relevância à religiosidade no contexto da atenção em saúde e saúde mental é considerá-la um traço nuclear da cultura das classes po-pulares, dimensão que, em sua natureza, reflete um inconformismo e protesto latentes.

A necessidade de aproximação da dimensão da espiritualidade anunciada pelas classes populares que demandam tratamento para problemas decorrentes do uso de álcool e outras drogas expressa tanto a demanda por um direito civil fundamental, o qual assume funções de apoio social em contextos de exclusão e desfiliação social, como a indispensabilidade por maiores investimentos na Raps. Tais expressões possuem claras convergências com a estratégia do PEP profissional pela emancipação humana a partir da defesa intransigente dos direitos humanos.

\section{À guisa de conclusão: tempos sombrios para a política de saúde mental}

Consideramos que a necessidade da religiosidade como elemento de apoio social para lidar com o sofrimento mental que decorre dos problemas com o uso de álcool e outras drogas é inversamente proporcional ao financiamento e pleno funcionamento da Raps. Desse modo, auferindo a utopia de uma sociedade sem manicômios, a partir de uma política de saúde mental forte, abrangente, humana e integral, a demanda pela dimensão da religiosidade como estratégia de apoio arrefecerá; o que não deve nos fazer prescindir, no atual contexto de trabalho na Raps, da constatação da religião de seus usuários como importante estratégia de amparo mútuo e encaminhamento de necessidades emergenciais.

O problema do enfrentamento às comunidades terapêuticas deve ser solucionado via fortalecimento da Raps, dos Centros de Atenção Psicossocial (Caps), sobretudo os de tipologia álcool e outras drogas (AD), das residências terapêuticas e outros serviços extra-hospitalares balizados nos princípios do tratamento em liberdade e na perspectiva da cidadania. Contudo, tempos sombrios circundam as experiências e as possibilidades de superação de uma vertente conservadora nos últimos anos para o campo da saúde mental, realidade que recrudesce a partir da pandemia da Covid19, dado o descompasso na gestão federal nesse campo.

No quadro atual, sobretudo após golpe político de 2016, as estruturas de atenção psicossocial têm sofrido processos de desfinanciamento 


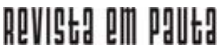

\} RELIGIÃO, COMUNIDADES - MAGALHÃES, V. P.; SANTOS, V. N. \}

DOI: $10.12957 /$ REP.2022.63447

como resultado da Emenda Constitucional (EC) $\mathrm{n}^{\circ}$ 95, que criou um teto para investimentos públicos. A lógica da atenção psiquiátrica tem dado sinais de retrocessos e de desconstrução da perspectiva da atenção psicossocial, como foi possível perceber nas declarações do coordenador, entre 2017 e 2019, de Saúde Mental, Álcool e outras Drogas do Ministério da Saúde, Quirino Cordeiro Júnior ${ }^{3}$, as quais sinalizariam a estrutura de uma nova política nacional de saúde mental.

Ademais, recentemente foi denunciada pela imprensa uma disposição criminosa do governo federal - através do Ministério da Saúde e da Coordenação de Saúde Mental, Álcool e outras Drogas, na pessoa da médica psiquiatra Maria Dilma Alves - em revogar 99 portarias que conformaram a reforma psiquiátrica no país por 20 anos. Dentre as medidas sinalizadas numa planilha que vazou à imprensa, estão: extinção do Programa de Volta para Casa; diminuição no financiamento dos consultórios de rua; extinção de Caps-AD; afrouxamento da necessidade de comunicação sobre internações involuntárias ao Ministério Público; e investimento em ambulatórios especializados em substituição aos atendimentos psicossociais nos Caps - medidas profundamente convergentes com as que a Associação Brasileira de Psiquiatria tem defendido publicamente.

Ao sucateamento da Raps soma-se o severo quadro de retração de direitos sociais, de desemprego, de desalento, de individualismo, de hedonismo-consumista, de desenvolvimento da biotecnologia e da Big Pharma num cenário propício para produção de superlucros, engendrando subjetividades marcadas pelo desamparo e depressão e pela desarticulação da perspectiva de futuro, fatores viabilizadores de todas as violências decorrentes do narcotráfico e do consumo abusivo de drogas (VASCONCELOS, 2016) - realidade trágica que é exponenciada em tempos de pandemia, a qual tem sido gerida e cultivada conscientemente pela gestão do executivo federal no intuito de ceifar a vida dos mais pobres e pretos.

Esse sucateamento reverbera em processos de sofrimento mental crônico, posto que os Caps, já desfigurados em razão de contingenciamento na política de saúde, apresentam estrutura deficitária para o devido atendimento e manejo de crises no território, o que estimula o acolhimento dos casos por hospitais psiquiátricos e comunidades terapêuticas, algumas vezes de forma compulsória. Em face de tal realidade, as estratégias dos movimentos sociais que se aglutinam em torno da luta antimanicomial caminham na direção de assumir táticas defensivas, sinalizando a necessidade de construção de um bloco histórico democrático-popular onde novamente seja possível avançar na luta pela consolidação de nossa reforma psiquiátrica.

\footnotetext{
${ }^{3}$ A nota técnica (no 11/2019 - CGMAD/Dapes/SAS/MS) produzida pelo coordenador-geral de Saúde Mental, Álcool e outras Drogas, entre outros retrocessos, legitima o tratamento com "eletroconvulsoterapia"; desconsidera a política nacional de redução de danos ao propor uma perspectiva de tratamento baseada na abstinência; e retoma a abertura de leitos em hospitais psiquiátricos (BRASIL, 2019b).
} 


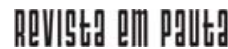

\} RELIGIÃO, COMUNIDADES - MAGALHÃES, V.P.; SANTOS, V. N.\}

DOI: $10.12957 /$ REP.2022.63447

Entre as táticas está compreender o papel da religião para as classes populares, traduzindo-a na sua relação com o acesso ao direito. Trata-se de mais um desafio a ser enfrentado na consolidação do projeto ético-político do Serviço Social brasileiro. 




\} RELIGIÃO, COMUNIDADES - MAGALHÃES, V. P.; SANTOS, V. N. \}

DOI: $10.12957 /$ REP.2022.63447

\section{Referências}

AMALADOSS, M. Religiões: violência ou diálogo? Revista Perspectiva Teológica, v. 34, 2002. Disponível em: https://doi.org/10.20911/21768757 v34n93p179/2002. Acesso em: fev. 2020.

AMARANTE, P. Loucos pela vida: a trajetória da reforma psiquiátrica no Brasil. Rio de Janeiro: Fiocruz, 1995.

BETTO, F. Paraíso perdido: viagens ao mundo socialista. Rio de Janeiro: Rocco, 2015.

BICALHO, P. P. G. de; BARBOSA, R. B.; SIMÕES, J. P. M. Promoção de direitos humanos no contexto de denúncias de violações em comunidades terapêuticas no Brasil. In: VASCONCELOS, E. M.; CAVALCANTE, R. (Org.). Religiões e o paradoxo apoio social - intolerância, e implicações na política de drogas e comunidades terapêuticas. São Paulo: Hucitec, 2019.

BRASIL. Ministério da Saúde. Departamento de doenças de condições crônicas e infecções sexualmente transmissíveis. O que é redução de danos? 2019a. Disponível em: http://www.aids.gov.br/pt-br/faq/23-o-que-e-reducao-dedanos Acesso em: 12 dez. 2019.

BRASIL. Ministério da Saúde. Secretaria de Atenção à Saúde. Departamento de Ações Programáticas Estratégicas. Coordenação-Geral de Saúde Mental, Álcool e outras drogas. Nota técnica n. 11/2019-cgmad/dapes/sas/ms. Traz esclarecimentos sobre as mudanças na política nacional de saúde mental e nas diretrizes da política nacional sobre drogas. 2019b. Disponível em: http:// pb pd.org.br/wp-content/uploads/2019/02/0656ad6e.pdf. Acesso em: 12 fev. 2019.

CAVALCANTE, R. A institucionalização clínica e política das comunidades terapêuticas e a sua relação com a saúde mental brasileira. In: VASCONCELOS, E. M.; CAVALCANTE, R. (Org.). Religiões e o paradoxo apoio social -intolerância, e implicações na política de drogas e comunidades terapêuticas. São Paulo: Hucitec, 2019.

CFESS. CFESS Manifesta, edição especial: em defesa do Estado laico! Brasília, 2016. Disponível em: www.cfess.org.br/arquivos/2015-CfessManifestaEstadoLaico-Site.pdf. Acesso em: 15 dez. 2019.

CHAUÍ, M. Cultura e democracia. São Paulo: Cortez, 1990.

CORDEIRO, J. G. Fundamentalismo - algumas considerações históricas sobre o fenômeno. In: DIAS, Z. M. (Org.). Os vários rostos do fundamentalismo: Fórum Ecumênico Brasil. São Leopoldo: Cebi, 2009.

DENADAI, M. C. V. B. O debate do legislativo brasileiro no campo das drogas. In: VASCONCELOS, E. M.; CAVALCANTE, R. (Org.). Religiões e o paradoxo apoio social - intolerância, e implicações na política de drogas e comunidades terapêuticas. São Paulo: Hucitec, 2019. 


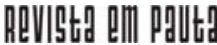

\} RELIGIÃO, COMUNIDADES - MAGALHÃES, V. P.; SANTOS, V. N. \}

DOI: $10.12957 /$ REP.2022.63447

FERNANDES, F. A Revolução burguesa no Brasil: ensaio de interpretação sociológica. São Paulo: Globo, 2006.

MARIANO, R. Expansão pentecostal no Brasil: o caso da Igreja Universal. Revista Estudos Avançados, v. 18, n. 52, 2004. Disponível em: http:// dx.doi.org/10.1590/S0103-40142004000300010. Acesso em: fev. 2020.

MARX, K. Crítica da filosofia do direito de Hegel, 1843. São Paulo: Boitempo, 2010.

NASCIMENTO, R. B. do. Laicidade: para repensar o humanismo. In: ENCONTRO ANUAL DE INICIAÇÃO CIENTÍFICA DA UNESPAR, 2, 2016. Disponível em: http://www.fecilcam.br/eventos/index.php/eaic/iieaic/paper/ viewFile/4276/1264. Acesso em: 15 dez. 2019.

PANASIEWICZ, R. Fundamentalismo religioso: história e presença no cristianismo. [2010]. Disponível em: http://www.educadores.diaadia. pr.gov.br/arquivos/File/2010/artigos_teses/ENSINORELIGIOSO/artigos/ 8fundamentalismo.pdf. Acesso em: 29 mar. 2017.

PARKER, C. Religião popular e modernização capitalista. Outra lógica na América Latina. Petrópolis: Vozes, 1996.

RANQUETAT JR., C. A. Laicidade, laicismo e secularização: definindo e esclarecendo conceitos. Revista Sociais e Humanas, v. 21, n. 1, 2008. Disponível em: https://periodicos.ufsm.br/sociaisehumanas/article/view/773. Acesso em: 15 nov. 2019.

VALLA, V. V. A crise de interpretação é nossa: procurando compreender a fala das classes subalternas. Educação e Realidade, v. 21, n. 2, 1996. Disponível em: https://seer.ufrgs.br/educacaoerealidade/article/view/71626. Acesso em: 18 dez. 2019.

VALLA, V. V. O que a saúde tem a ver com a religião? In: VALLA, V. V. (Org.). Religião e cultura popular. Rio de Janeiro: DP\&A, 2001.

VASCONCELOS, E. M. Reforma psiquiátrica, tempos sombrios e resistência: diálogos com o marxismo e o Serviço Social. Campinas: Papel Social, 2016.

VASCONCELOS, E. M. O campo das ciências das religiões, o paradoxo apoio social - intolerância e as práticas no lidar com situações existenciais/ sociais limite e com as drogas. In: VASCONCELOS, E. M.; CAVALCANTE, R. (Org.). Religiões e o paradoxo apoio social - intolerância, e implicações na política de drogas e comunidades terapêuticas. São Paulo: Hucitec, 2019.

DOI: $10.12957 /$ rep.2022.63447

Recebido em 20 de junho de 2021.

Aprovado para publicação em 23 de setembro de 2021.

A Revista Em Pauta: Teoria Social e Realidade Contemporânea está licenciada com uma Licença Creative Commons Atribuição 4.0 Internacional. 